\title{
Trámite de la sucesión intestamentaria ante notario público en este Estado de Jalisco
}

\author{
César Jiménez Hernández \\ Estudiante de la Maestría en Derecho, Universidad de Guadalajara. México \\ lic_cesarjh@hotmail.com
}

Enviado: $18 / 12 / 2017$

Dictaminado: 26/02/2018

\section{Resumen}

La presente investigación aborda el problema que representa la imposibilidad de que el Notario Público tramite una sucesión desde la etapa de denuncia, aún cuando tenga la cualidad de perito en derecho, de distinguir perfectamente entre las personas que se piensan herederos, y quienes realmente lo son, por ley. Es así como podemos cuestionarnos sobre si, ¿Debería el notario tramitar las sucesiones intestamentarias desde el inicio o necesariamente debe declararse por un juez quiénes son los herederos y albaceas del de cujus? Es necesario analizar la naturaleza jurídica del procedimiento para comprender que el Notario es plenamente capaz de llevar la primera etapa sucesoria con total apego a la ley y con un mejor grado de satisfacción de los familiares, además de una importante descongestión de los órganos jurisdiccionales. Las bases doctrinales usadas, en conjunto con los resultados y sucesiones tramitadas ante notarios de diversos estados de la república, así como de diversos países latinoamericanos, comprobarán que las sucesiones intestamentarias ante notario son benéficas para los familiares.

Palabras clave: Sucesión, notario, órganos jurisdiccionales, intestamentaria.

\section{Processing of intestate succession before a notary public in this State of Jalisco}

\begin{abstract}
This research addresses the problem that represents the inability of the Notary Public to
\end{abstract}


process a succession from the first stage, even when it has the status of expert in law, to distinguish perfectly between people who think they are Heirs, and who really are, by law. Is this how we can question whether, should the notary process the intestate successions from the beginning or should it necessarily be declared by a judge who are the heirs and executors of the de cujus? It is necessary to analyze the legal nature of the procedure in order to understand that the Notary is fully capable of taking care of the first stage of succession with total adherence to the law, and with a better degree of satisfaction of the relatives, in addition to an important decongestion of Jurisdictional courts. The doctrinal bases used, in addition to the results and successions processed before notaries of various states of the Republic, as well as of several Latin American countries, will verify that the intestate successions before notary have more benefits for their families.

Key words: succession, notary, jurisdictional bodies, intestate.

\section{Sumario}

I. Introducción; II. Problema; III. Sucesión legítima notarial en México y el Derecho Comparado; 3.1. La realidad normativa nacional; 3.2 Análisis comparativo, normativa y doctrina; IV. Conclusiones y propuestas; Bibliografía.

\section{Introducción}

Entendemos la sucesión como el medio por el cual una persona toma u ocupa el lugar de otra con respecto a sus derechos, es decir, lleva de forma implicita la sustitución de una persona en cuanto a la titularidad de derechos y obligaciones, por otra que los adquirirá a falta de la primera. En el caso de la muerte de una persona, estamos frente a una sucesión de carácter específicamente hereditario, es decir, que es en cuanto a la herencia de la persona que fallece, misma que puede realizarse sobre todos los bienes del de cujus, o sobre determinados bienes, que se llaman legados.

La palabra sucesión, proviene del latín Successio, y se usa precisamente para designar la transmisión del patrimonio que tiene lugar a la muerte de una persona. Según el derecho romano, en este caso, y como ya lo decíamos, nos 
interesa la sucesión mortis causa, que era la transmisión a uno o varios herederos del patrimonio ya que casi siempre se transmite a la muerte del autor de la sucesión. La sucesión se puede definir de forma general, como la sustitución de una persona por otra en determinada relación jurídica ${ }^{1}$, sin embargo, algunos autores como Rojina Villegas ${ }^{2}$ consideran que es posible marcar una diferencia entre lo que se comprende como sucesión, y el derecho hereditario, misma que es comparable de manera género-especie. Así, el derecho sucesorio hace referencia a la sustitución de una persona por otra en una situación jurídica particular, mientras que el derecho hereditario tiene como objeto de estudio la sucesión de una persona por otra en cuanto a sus bienes, derechos y obligaciones. De la misma forma, Asprón Pelayo nos dice que "suceder" tiene una conotación más restringida, la cual se refiere a la transmisión de bienes por causa de muerte. Por otro lado, el artículo 2652 del código civil del Estado de Jalisco señala, en el primer artículo del capítulo de sucesiones, que:

"Herencia es la sucesión de todos los bienes del difunto y de todos los derechos y obligaciones que no se extinguen por la muerte."

Lo que nos deja con una definición muy vaga del concepto. Los romanos ya contemplaban como forma de adquirir bienes per universitatem, es decir, de forma universal, a la sucesión por causa de muerte del autor ${ }^{3}$. Para ellos, el patrimonio se componía de dos partes, una activa y una pasiva, bienes y deudas, y si muere, el derecho romano le da un continuador de su persona llamada heredero, que se convierte en dueño del patrimonio en su lugar, y queda también obligado a pagar todas las deudas como si las hubiese contraído.

Los acreedores encuentran en él un nuevo deudor y tienen la forma de garantizar en el patrimonio del de cujus. Existían entonces dos formas de designar el heredero: por la ley y por el difunto, de tal suerte que los romanos ya reconocían como la importancia de la voluntad del difunto sobre la del legislador para la elección de un heredero, y la ley de las 12 tablas sanciona para el padre de familia

1 Asprón Pelayo, J. M. (2008). Sucesiones. México: Mc Graw Hill.

2 Rojina Villegas, R. (1994). Derecho Civil Mexicano IV. México: Porrúa.

3 Petit, E. (2011). Tratado Elemental de Derecho Romano. México: Porrúa. 
el derecho de elegir por sí mismo quién debía continuar con su personalidad, manifestando su vountad en un acto llamado testamento. Sin embargo, el padre podía morir intestato, sin haber hecho un testamento válido, entonces solamente es la ley quien designa heredero. De manera que podemos decir que, según el derecho civil romano, hay dos clases de sucesiones: una regulada por la voluntad del difunto, o sucesión testamentaria, y la otra por ley, o sea la sucesión $A b$ intestato.

Así pues, se puede afirmar que en el derecho romano, quien estaba facultado para llevar a cabo y vigilar la sucesión, era el administrador de justicia y no una figura diversa y alejada del ámbito judicial. Sin embargo, los sistemas jurídicos han cambiado y ahora el estado ha delegado múltiples funciones a personas ajenas al poder público, tema que abordaremos en posteriores líneas.

Desde el punto de vista de la función práctica, el derecho sucesorio encuentra su razón de ser en la exigencia de proveer a la suerte de un patrimonio que continúa existiendo, mientras ha fallecido su titular y se ha extinguido todo vínculo entre aquél y ese patrimonio ${ }^{4}$.

Una vez delineados los diversos conceptos que tienen relación con el tema, es preciso señalar que tanto los diversos cuerpos normativos como la doctrina, coinciden en que las sucesiones se pueden clasificar en:

- Testamentaria. Que se rige por la voluntad del testador, es decir, el autor de la sucesión que dejó una disposición testamentaria.

- Legítima o intestamentaria. En la que se aplica la voluntad que la ley presuntamente considera que sería la del autor de la herencia.

Aunque algunos autores como el precitado Asprón Pelayo, consideran que existe una sucesión mixta, que es la que es en parte testamentaria y en parte legítima, por no haber dispuesto el testador de la totalidad de sus bienes mediante un testamento. Sin embargo, algunos consideran que no se debe subclasificar en mixta, sino que simplemente se trata de dos diferentes, en donde una parte es

4 Arguello, L. R. (1998). Manual de derecho romano. Buenos Aires: Astrea 
testamentaria y la otra, por exclusión, no lo es. Lo anterior es así, sobre todo si consideramos que en la práctica jurídica, cuando ocurre esto suele sobreseerse un juicio sucesorio en la parte que corresponde a uno de los dos tipos de sucesión, y continuarse con la otra, y el juzgador no declara abierta la sucesión mixta.

También es posible clasificar las sucesiones en cuanto al procedimiento que se sigue para llevar a cabo la tramitación de la sucesión, y en donde tenemos que existen:

- La Judicial. Que es la tramitación que se sigue ante el juez competente de primera instancia, y por regla, toda sucesión, tanto testamentaria como legítima, puede tramitarse ante juez.

- La extrajudicial o notarial. Esta sucesión se lleva a cabo ante el notario público y se encuentra más restringida a ciertos casos señalados en el Código de Procedimentos del Estado de Jalisco y la Ley del Notariado.

Para efecto del presente estudio, la sucesión que resulta de interés, es la sucesión legítima o intestamentaria, y su relación con el Notario Público, en el Estado de Jalisco, en cuanto a las facultades que tiene éste de que las partes acudan ante él a realizar los actos tendientes concluir la tramitación de la sucesión.

Por regla general, la sucesión testamentaria puede ser tramitada ante notario desde su inicio cumpliendo ciertos requisitos legales que se abordarán en el capítulo correspondiente, mientras que la legítima, sólo podrá ser tramitada en sede notarial una vez que haya sido radicada en el juzgado competente, y luego de haber concluído las primeras etapas de la sucesión, habiendo sido nombrados herederos y albacea, y que estos manifiesten su conformidad con continuar el trámite ante notario. Esta situación la consideramos innecesaria por las razones que abordaremos más adelante.

En cuanto al tema del Notario Público y su marco legal, encontrmos lo siguiente. De acuerdo con la Ley del Notariado, Notario Público es el profesional del derecho que desempeña una función pública, investido por delegación del Estado a través del Titular del Poder Ejecutivo, de la capacidad de formalizar y dar fe para hacer 
constar hechos, actos y negocios jurídicos a los que se quiera o deba dar autenticidad y seguridad jurídica. Por otro lado, para Jorge Ríos Hellig, el notario es;

"un particular, profesional del derecho, que después de sustentar diversos exámenes, tanto de aspirante como de oposición, ejerce la carrera u oficio notarial con objeto de brindar seguridad jurídica y certeza en las transacciones de las que da fe, siempre con un alto nivel de profesionalismo, de independencia frente al poder público y los particulares, una completa imparcialidad para sus clientes y una autonomía en sus decisiones, las cuales sólo tienen por límite el marco jurídico y el estado de derecho. ",

De esta definición y lo anteriormente plasmado, podemos concluir sin duda que el notario tiene plena capacidad para ser eficaz en el conocimiento y tramitación de sucesiones intestamentarias desde su denuncia, por las razones que se expresan más adelante.

\section{Problema}

En el estado de Jalisco, las sucesiones intestamentarias tienen que ser innecesariamente radicadas ante el juzgado de primera instancia del último domicilio del autor de la sucesión, para que luego se declaren los herederos, se nombre un albacea y, en su caso, se derive la tramitación de la sucesión ante el notario elección de los herederos.

Esto genera que los juzgados tengan que conocer inicialmente de cuestiones que el notario es perfectamente capaz de tramitar, representando una carga innecesaria para los ya atiborrados juzgados.

Vendría bien al campo jurídico jalisciense, permitir al Notario tramitar la sucesión desde un inicio, puesto que ello traerá más satisfacción para los herederos que consideren pertinente acudir ante él en lugar de contratar un abogado para llevarla a cabo ante el juzgado, en aquellos casos en los que no exista conflicto entre los mismos y sea plenamente acreditable su calidad de presuntos herederos frente al notario con las actas de registro civil correspondientes.

5 Ríos Hellig, J. (1998). Práctica del derecho Notarial. México: Mc Graw Hill. P. 40 


\section{Sucesión legítima notarial en México y el Derecho comparado}

\subsection{La Realidad Normativa Nacional}

\section{El artículo 3118 del Código Civil del Estado de Jalisco establece en su primer párrafo que:}

"Cuando todos los herederos sean mayores de edad, exista testamento público abierto, podrán los interesados tramitar el negocio sucesorio ante notario público que tenga su jurisdicción en el domicilio donde correspondería conocer a la autoridad judicial del mismo, en los términos del Código de Procedimientos Civiles. También en los casos de sucesión legítima, o testamento público cerrado y ológrafo, una vez que hubieren sido reconocidos los herederos, y designado el albacea, podrán los interesados separarse del trámite judicial y concurrir a notaría para la prosecución del negocio”.

Son varios los estados que tienen legislación al respecto, entre ellos, la Ley del Notariado del Distrito Federal, establece en su Artículo 166 que:

"En los términos de esta ley se consideran asuntos susceptibles de conformación por el Notario mediante el ejercicio de su fe pública, en términos de esta Ley:

I.- Todos aquellos actos en los que haya o no controversia judicial, los interesados le soliciten haga constar bajo su fe y asesoría los acuerdos, hechos o situaciones de que se trate;

II.- Todos aquellos en los que, exista o no controversia judicial, lleguen los interesados voluntariamente a un acuerdo sobre uno o varios puntos del asunto, o sobre su totalidad, y se encuentren conformes en que el notario haga constar bajo su fe y con su asesoría los acuerdos, hechos o situaciones de que se trate, siempre que se haya solicitado su intervención mediante rogación.

III.- Todos aquellos asuntos que en términos del Código de Procedimientos Civiles conozcan los jueces en vía de jurisdicción voluntaria en los cuales 
el notario podrá intervenir en tanto no hubiere menores no emancipados o mayores incapacitados. En forma especifica, ejemplificativa y no taxativa, en términos de este capítulo y de esta ley:

\section{Vemos que el legislador de la asamblea legislativa de la Ciudad de México consideró correcta la opción de iniciar el trámite sucesorio ante el notario.}

\section{En el mismo sentido el estado de Yucatán en su Ley del Notariado establece que:}

“Artículo 112.- En los términos de esta ley, pueden ser materia de la actuación del Notario Público mediante el ejercicio de su fe pública los actos o hechos jurídicos siguientes:

I.- Todos los actos en los que no haya controversia judicial y los interesados soliciten voluntariamente al Notario Público, hacer constar bajo su fe pública, los acuerdos, hechos, situaciones y resoluciones de que se trate, siempre que la ley no establezca competencia exclusiva al Poder Judicial de Estado para conocer de estos casos, o cuando se deba de tener la intervención legal del Ministerio Público como representante social, de menores e incapaces, o cuando se afecten derechos de terceros, $y$

II.- Los asuntos que de acuerdo al Código de Procedimientos Civiles de Yucatán y al Código de Procedimientos Familiares del Estado de Yucatán, sean de trámite en vía de jurisdicción voluntaria, salvo cuando se trate de alimentos provisionales que puedan afectar derechos de menores e incapaces o cuando deba de tener intervención legal el Ministerio Público como representante social en términos de los artículos 847 del Código de Procedimientos Civiles de Yucatán o 680 del Código de Procedimientos Familiares del Estado de Yucatán, según corresponda.

Artículo 112 Bis.- En los términos de esta ley, se consideran asuntos susceptibles de tramitación ante Notario Público mediante el ejercicio de su fe pública:

I.- Las sucesiones testamentarias o intestadas en términos de lo dispuesto por el Capítulo I del Título Tercero del Libro Tercero del Código de Procedimientos Familiares del Estado de Yucatán;" 
Como se puede apreciar, éstas legislaciones que sirven de ejemplo, llevan la delantera sobre la del Estado de Jalisco, toda vez que contemplan la posibilidad de tramitar la sucesión ante el Notario Público de su elección desde un inicio, con sus respectivos presupuestos, desde luego.

\subsection{Análisis Comparativo. Normativa y Doctrina}

Dentro del marco jurídico de nuestro estado, encontramos que, de acuerdo con la Ley del Notariado del Estado de Jalisco, en su artículo 3, señala:

"Notario Público es el profesional del derecho que desempeña una función pública, investido por delegación del Estado a través del Titular del Poder Ejecutivo, de la capacidad de formalizar y dar fe para hacer constar hechos, actos y negocios jurídicos a los que se quiera o deba dar autenticidad y seguridad jurídica".

Además, el Notario Público actúa siempre respetando ciertos principios enmarcados en la ley, que nos permiten afirmar su capacidad para tramitar sucesiones en los términos propuestos más adelante, en este caso, el artículo séptimo de la Ley del Notariado, en sus fracciones III, IV, V, VI y VII, establece lo siguientes principios notariales:

"III. Formalidad escrita o instrumental del documento notarial: su función se materializa en la autorización formal del instrumento que queda como un documento histórico que puede hacerse valer a futuro por las partes y también puede ser referenciado por terceros;

IV. Imparcialidad y rectitud: el notario, al asesorar personalmente a las partes debe mantener una conducta neutral, de concentrador de las declaraciones de voluntad de las partes, sin que le sea permitido privilegiar los intereses de una parte sobre otra;

V. Legalidad: el notario debe actuar siempre con sujeción a la Constitución Politica de los Estados Unidos Mexicanos, a la Constitución del Estado, a esta Ley y a todas las normas de de carácter civil, mercantil, fiscal, y demás leyes que tengan aplicación en el acto notarial de que se trate, como profesional que es en derecho; 
VI. Rogación: el notario debe actuar a petición de parte legítima, no de oficio;

VII. Inmediación: sólo le es dable al notario dar fe de aquello que percibe por los sentidos y lo que las partes están aportando;”

Por lo que, de acuerdo con sus funciones y los principios rectores de la función notarial, el notario público estaría en posibilidades de garantizar que el negocio sucesorio legítimo se llevará de manera adecuada, respetando los derechos de los interesados en la sucesión.

Es necesario recordar, que el notario es un especialista en derecho y asesor, y como tal está plenamente capacitado para informar a las personas de la situación que señala la ley respecto de los herederos que legítimamente tienen derecho de serlo, y que por ende puede hacerle saber a las partes su condición como tales.

Es por esto que se vuelve imprescindible analizar detenidamente las diversas posibilidades que existen en este campo, ya que de otorgarse al notario público la posibilidad de llevar a cabo desde el inicio una la sucesión legítima, entre otras cosas, se podrían acortar los tiempos que se requieren para llevar el negocio, y con ello beneficiar a los ya congestionados tribunales en materia familiar, al disminuir su carga de trabajo.

Como se puede observar, no existe una figura que permita que el notario público conozca del negocio de la sucesión legítima desde el inicio de manera automática y sin requisitos previos, al igual que en la norma del estado de Jalisco que también permite la presentación de este negocio ante notario público, siempre y cuando se cumplan ciertos requisitos de ley previos a la petición de la sucesión legítima ante notario.

En materia internacional, la legislación de la Republica de Colombia, es destacable por los siguientes aspectos:

- Se pueden presentar ante notario negocios por cualquier cuantía.

- Los herederos, legatarios y cónyuge sean capaces.

- Que las partes procedan en común acuerdo.

- Solicitar por escrito mediante apoderado (Abogado Titulado). 
De la misma manera la República de Costa Rica contempla en su Código Notarial las siguientes condiciones para llevar acabo la Sucesión Legitima ante el Notario Público.

- Los herederos, legatarios y cónyuge sean capaces.

- Que no figuren menores de edad entre los interesados.

Para la Republica de Perú en su Ley de Competencia Notarial en Asuntos no Contenciosos tenemos que:

- Los interesados deben acudir por su propio derecho ante el notario.

- Los interesados deben dar su consentimiento y proceder por común.

- Si algún interesado entra en desacuerdo con alguna de las partes, no se podrá continuar con el negocio ante el notario.

La Republica de Argentina, por su parte, no contempla esta figura legal en sus códigos, sin embargo, se ve necesario que se adopte esta en su código, para adaptar las leyes a las necesidades sociales.

Autores como Baqueiro Rojas, consideran útil la opción de elegir la vía notarial para tramitar una sucesión en sede notarial desde sus inicios, contemplando los siguientes aspectos. Para el referido Baqueiro Rojas ${ }^{6}$ del trámite de la sucesión ante notario se deben hacer constar cuatro actas:

- La aceptación de herederos y del albacea de solicitar la intervención del notario.

- La de conformidad y protocolización del inventario y avalúo formlulados por el albacea y los herederos, de común acuerdo.

- Las cuentas por parte de la administración.

- La aprobación de la partición de bienes que se realice.

6 Baqueiro Rojas, E., \& Buenrostro Báez, R. (2007). Derecho sucesorio. México: Oxford. 
La legislación de Jalisco no menciona exactamente esos detalles, y el Código de Procedimientos Civiles del Estado de Jalisco simplemente señala que el notario puede conocer de la sucesión intestamentaria luego de que se haya radicado ante el juzgado competente, declarado herederos y designado albacea.

Esto partiendo de la premisa de que el nombramiento de herederos y designación de albacea son facultades del ente jurisdiccional, apreciación que nos parece incorrecta y ya fue rebatida por la nueva Ley del Notariado del Distrito Federal, puesto que si bien es cierto que el notario no tiene facultades para resolver controversias, es un perito en derecho y sabe perfectamente que no es el juez quien decide quién es heredero de un de cujus, sino la ley. Esto es, que el conocedor del derecho sabe que el código civil señala claramente quiénes tienen derecho a heredar preferentemente en la sucesión intestamentaria, y cuáles parientes excluyen a los otros. Así, basta que ante el notario comparezcan quienes puedan acreditar el entroncamiento con el autor de la sucesión, para que el notario esté en condiciones de hacerles saber quién tiene derecho a heredar de acuerdo con la ley, y en caso de que ellos lo entiendan y den su visto bueno, continuar con la tramitación de la sucesión ante él.

Como ya señalamos anteriormente, el Notario, en su calidad de especialista en derecho, es también asesor, mediador, conciliador, y árbitro, por lo que está perfectamente capacitado para hacerles saber a las partes los derechos sucesorios que tienen, según lo establece la misma ley, y para lograr el entendimiento y acuerdo entre ellos, para que se esté en posición de tramitarse la sucesión ante él. De esta forma, y en el mismo tenor manejado por la Ley del Notariado para el Distrito Federal, hoy Ciudad de México, la sucesión podría iniciarse ante el notario que los denunciantes elijan. Desde luego este esquema tiene sus excepciones, tales como que si el que pretende denunciar es concubino/a del de cujus, o si existen menores o incapaces, no es posible realizarla ante su fe, sin embargo, estas cuestiones quedan a salvo para ser tramitadas de forma judicial, toda vez que el notario no está facultado para dilucidar si la persona es o no concubina, y para ello existen medios de prueba que deben ventilarse ante un juzgador, quien deberá decidir si la persona acredita o no el concubinato.

También es posible argumentar, atendiendo al argumento de A majori ad minus, que es cuestionable que al notario se le permita buscar lograr un acuerdo 
entre las partes dentro de la etapa de partición y adjudicación de la herencia, y no se le permita buscar un acuerdo para que los que se creen con derecho a heredar, comprendan quiénes son los que tienen realmente derecho a ello, con base en la ley.

Es decir, la parte más conflictiva de una sucesión, es, discutiblemente, la partición de los bienes, y no el nombramiento de herederos, toda vez que, aunque este último llega a causar conflicto, también es cierto que viene dado por la ley, por lo que a pesar del conflicto, las partes deben entender si tienen o no derecho a hereder, sitaución diferente a la partición de los bienes, puesto que sobre la determinación de los mismos y la fijación de cuál bien le toca a quién en la intestamentaria, es necesario atenerse al acuerdo entre ellos.

Así también, es posible afirmar que para un heredero podría ser más perjuicioso, el hecho de que un bien que le pudo corresponder se le adjudique a alguien más, y no tan perjuicioso que no sea tomado en cuenta como heredero en el momento que se tramita la sucesión ante notario, puesto que aún tiene la acción de petición de herencia en su favor, misma que puede ejercitar antes de que se adjudiquen bienes. Entonces, es posible preguntarnos, atendiendo al previamente invocado argumento A majori ad minus ¿Por qué al notario se le impide intervenir en una etapa que es presumiblemente menos perjuiciosa para los herederos, mientras que se le permite intervenir en una que lo es más?.

Sobre el tema del procedimiento para localizar disposiciones testamentarias, hay que hacer el siguiente señalamiento. De acuerdo a la Ley del Notariado del Estado de Jalisco, el notario deberá recabar información de la Procuraduría Social, del Archivo de Instrumentos Públicos y del Registro Público de la Propiedad, respecto de cual sea la última disposición testamentaria que tengan registrada como otorgada. Luego, una vez recibida la información a que se refiere este artículo, dispondrá la publicación de un aviso en un periódico de mayor circulación y en el periódico oficial "El Estado de Jalisco", en los que se informe sobre la tramitación sucesoria. Como ya lo dijimos, el Notario está plenamente facultado para hacerles saber a las partes lo que la ley señala en materia sucesoria, sobre quiénes deben ser los herederos, de manera que todos lo comprendan y acepten firmar la primer escritura, donde manifiesten su voluntad de tramitar la sucesión ante dicho notario. 
Hecho lo anterior, el notario estaría en posición de abrir canales de comunicación buscando se pongan de acuerdo con el nombramiento de un albacea, y una vez conseguido, se habrá logrado cumplir la primera parte de la sucesión, y se podrá continuar en los términos que ya establece el código de procedimientos.

Así las cosas, es evidente que el notario está plenamente facultado para hacerles saber a las partes lo que la ley señala en materia sucesoria, sobre quiénes deben ser los herederos, de manera que todos lo comprendan y acepten firmar la primer escritura, donde manifiesten su voluntad de tramitar la sucesión ante dicho notario.

Para reforzar anteriores argumentos, podemos tener en cuenta lo que dice el siguiente criterio aislado:

SUCESIÓN TESTAMENTARIA ANTE NOTARIO. LAS CUESTIONES QUE ENTRAÑEN OPOSICIÓN, COMO LAS ACCIONES RELACIONADAS CON LA RENDICIÓN DE CUENTAS, ENTREGA DE BIENES Y REEMBOLSO DE GASTOS, DEBEN EJERCERSE EN LA VIA ORDINARIA CIVIL.

Las reglas establecidas en los artículos 784, 785, 786, 787, 788, 845, 851 y 852 del Código de Procedimientos Civiles para el Distrito Federal (tramitación de aspectos contenciosos y conclusión de los mismos, así como de las secciones, mediante la emisión de resoluciones), son propias de los juicios sucesorios testamentario e intestado, y de ningún modo pueden aplicarse a la testamentaría extrajudicial, que coincide con aquéllas en ciertas notas (reconocimiento de derechos hereditarios, inventario y partición), aunque difiere en un aspecto fundamental: la exclusión de toda cuestión contenciosa. Se entiende que así ocurra, dado que el notario carece de facultades jurisdiccionales, es decir, de control y decisión de un proceso, y es ajeno al Poder Judicial, razón por la que el trámite seguido ante él tiene un carácter extrajudicial. Esa particularidad de las testamentarías ante notario aleja a éste de cualquier aspecto debatido que necesite dilucidarse mediante un fallo jurisdiccional, y especificamente, por tratarse de materia sucesoria, judicial. De esa manera, la existencia de oposición de algún aspirante a la herencia o de cualquier acreedor, compele al fedatario público a suspender su intervención, bien por haberse planteado ante él, o en sede judicial. 
Todo ello, se desprende de la interpretación sistemática de los artículos 872, 873, 874, 875 y 876 del Código de Procedimientos Civiles para el Distrito Federal, y 167, 170, 171, 173 y 177 de la Ley del Notariado para el Distrito Federal. No corresponde, entonces, al fedatario público decidir las controversias que surjan en relación con la testamentaría que tramita, sino a la autoridad judicial, quien las sustanciará en términos del código procesal civil, el cual enuncia la tramitación de cuestiones incidentales dentro de las secciones de sucesión, inventario, partición, e inclusive, administración. A pesar de esa previsión legal, si existe una cuestión litigiosa derivada de una testamentaría extrajudicial no será factible su tramitación incidental, porque esa vía accesoria presupone la existencia de una principal, o sea, la sección correspondiente, y en el caso de la testamentaría ante notario ninguna sección existe en la forma establecida para los juicios sucesorios seguidos ante la autoridad judicial, aunque se cumpla esencialmente con el contenido de ellas, al producirse el reconocimiento de derechos hereditarios, el inventario y la partición. De cualquier manera, aunque pudiera estimarse que la testamentaría extrajudicial equivale a la vía principal, su carácter ajeno a toda contienda, impediría sustanciación incidental de cualquier tipo. Queda, por tanto, la opción de iniciar la vía principal judicial, concretamente la ordinaria civil, y sustanciar en ella las cuestiones litigiosas que surjan en la testamentaría, es decir, aquellas que entrañen oposición, como son las acciones relacionadas con la rendición de cuentas, el pago de gastos y la entrega de bienes, incluida la indemnización por la privación de la posesión?

De la interpretación de la anterior tesis aislada, podemos advertir que la razón para que el notario no conozca una sucesión intestamentaria desde su inicio, responde al hecho de que el mismo no tiene facultades jurisdiccionales, y que en caso de existir una controversia, es necesario que derive el procedimiento al juez competente.

Sin embargo, si analizamos las etapas del proceso de sucesión intestamentaria, podemos ver que existen dos momentos fundamentales en los cuales es más factible que las partes entren en conflicto, uno de ellos es la declaratoria de herederos, en donde podría presentarse un conflicto en razón

7 Novena Época, Registro: 171593, Instancia: Tribunales Colegiados de Circuito, Tipo de Tesis: Aislada, Fuente: Semanario Judicial de la Federación y su Gaceta, Tomo XXVI, Agosto de 2007, Materia(s): Civil, Tesis: I.3o.C.634 C, Página: 1856 
de si debería admitirse o no a un heredero como legítimo, sin embargo, es menester recordar que el notario es un perito en derecho, y que los herederos en sucesión legítima no son determinados por el juez de forma arbitraria, sino que la ley es quien señala cuál de los parientes debe exlcluir a otros, en razón de su cercanía, de tal suerte que siendo el notario un perito en derecho, mediador, conciliador y árbitro, es perfectamente capaz de señalarle -y hacer entender- a los comparecientes en el momento, sobre quién es quien tiene derecho a heredar en razón de lo que señala la ley. El otro momento es cuando es momento de realizar el proyecto de partición y adjudicación, el cual es presumiblemente el que trae más controversias, puesto que debe establecerse quién se adjudica cada bien. Así, podemos preguntarnos ¿por qué es permitido que el notario intervenga en la etapa de partición y adjudicación, que es la más litigiosa, y no en la de designación de herederos? Es entonces que se requiere que planteemos la posibilidad de que la sucesión intestamentaria se denuncie directamente ante un notario, quien puede recabar las actas de defunción, nacimiento y matrimonio de quienes se crean con derecho a heredar y comprueben el entroncamiento con el de cujus, y quien está facultado para girar oficios a las dependencias que tienen registros de disposiciones testamentarias a efecto de que manifiesten si tienen alguna a su cargo, y que luego puede publicar los edictos necesarios para convocar a quienes se crean con derecho a heredar para que comparezcan a su notaria, y que una vez concluído ese proceso, y con los elementos que tiene a su disposición, les haga saber a los interesados quiénes tienen el derecho a heredar conforme a la ley, para que en caso de controversia, quien sea excluído pueda hacerlo valer mediante a acción de petición de herencia correspondiente.

Si el notario tuviere éxito en esta etapa, la sucesión podría continuar teniendo como herederos a quienes el notario - en estricta interpretación de la ley, y con consentimiento de los interesados- señale para tal efecto, de manera que el trámite podría concluírse sin haber necesidad de poner en movimiento el aparato jurisdiccional.

Esto es así, porque no existe una justifiación más allá de lo establecido por la Ley del Notariado, para que el notario no pueda tramitar la sucesión desde el inicio. 
También podemos interpretar lo que dice el segundo tribunal colegiado en materia civil del segundo circuito en la siguiente tesis:

“HEREDEROS, SU CALIDAD JUICIOS TESTAMENTARIOS, CUANDO SE DEFINE.

Si bien es verdad que el objeto de someter los juicios testamentarios a la autoridad judicial lo es el que se cumplan las formalidades legales, ello no implica que la calidad de heredero se origine hasta que el Juez asi lo declare, como ocurre en los juicios intestamentarios, ya que esa calidad se deriva en principio del propio testamento, que es un acto jurídico unilateral, personalísimo, revocable y libre, por el cual una persona capaz transmite sus bienes, derechos y obligaciones, que no se extinguen por la muerte, a sus herederos o legatarios y se ve corroborado con el reconocimiento, que en la junta a que alude el artículo 940 del Código de Procedimientos Civiles vigente en el estado haga el juez a los herederos cuya capacidad no ha sido objetada, nombrados en un testamento no impugnado, de conformidad con lo dispuesto por el artículo 947 del ordenamiento legal citados."

De esta tesis, se puede advertir que el objeto de someter la sucesión a un juez es que se cumplan todas las formalidades legales, mismas que pueden ser perfectamente cumplidas y supervisadas por el notario, quien es un perito en derecho, por definición legal, y tal y como lo demuestra al velar por la legalidad de todo tipo de actos jurídicos.

Además, se lee en la citada tesis, que calidad de heredero en el caso de la sucesión testamentaria, no depende de que sea reconocida por el juez, sino que tal calidad viene otorgada por el testamento, de la misma forma que la calidad de heredero en la sucesión intestamentaria proviene de la ley, no de lo que dictamine el juez, quien únicamente está verificando que se cumplan las formalidades legales que, como ya señalamos, pueden ser supervisadas por el notario.

Debemos resaltar que para el autor Jorge Ríos Hellig el notario también es un controlador de la legalidad de los actos, y un intérprete de normas ${ }^{9}$. De tal suerte que está plenamente facultado para dar fé y vigilar la legalidad de una

8 Octava Época, Registro: 209987, Instancia: Tribunales Colegiados de Circuito, Tipo de Tesis: Aislada, Fuente: Semanario Judicial de la Federación, Tomo XIV, Noviembre de 1994, Materia(s): Civil, Tesis: II. 20. C.T. 2 C, Página: 451

9 Ríos Hellig, J. (2012) La práctica del Derecho Notarial. México: Mc. Graw-Hill, pag. 45 
designación de herederos y albacea.

De esta manera, se afirma que el notario está capacitado, y debería poder tramitar las sucesiones intestamentarias que ante él se desearan ventilar desde el inicio, siempre y cuando los comparecientes puedan acreditar plenamente su capacidad, su entroncamiento con el de cujus, su defunción, y su último domicilio. Sin embargo, quedarían excluídos del presente beneficio los concubinos y las sucesiones donde las partes manifiesten la existencia de un presunto heredero incapaz, pero se abre la puerta para que todas aquellas familias que han perdido un familiar y tienen buena realación entre ellos, acudan con el notario para tramitar de forma completa su sucesión, la que será llevada de manera más pacífica para todos. Una vez denunciada de esta forma y como ya apuntábamos, el notario deberá obtener información de la Procuraduría Social, del Registro Público de la Propiedad y del Archivo de Intrumentos públicos, para que revelen si ante ellos se encuentra registrada alguna disposición testamentaria. Luego, publicará los edictos de ley para convocar a quienes se crean con derecho a heredar del de cujus. Una vez terminadas esas etapas, está en posición de hacer del conocimiento de las partes quién tiene derecho a heredar conforme a la ley, puesto que es plenamente capaz de saberlo, en su carácter de perito, a luego poner de acuerdo a los herederos para que nombren a un albacea, y continuar el trámite por las etapas que correspondan.

\section{Conclusiones y propuestas}

De acuerdo a lo expuesto en el presente artículo, debe permitirse al notario tramitar las sucesiones intestamentarias que encajen con los supuestos señalados, donde los presuntos herederos comparezcan acompañados de dos testigos que señalen el último domicilio del de cujus, sus actas del registro civil que acrediten su vínculo con el de cujus, de común acuerdo, así como el acta de defunción, que manifiesten que no saben de alguien más con derecho a heredar, de forma que el notario levantará constancia de su deseo de tramitar la sucesión en su notaria, recabará la información testamentaria de las dependencias que poseen 
registros de testamentos, publicará los edictos de ley convocando a quienes se crean con mejor derecho a heredar y les avisará que la sucesión se lleva a cabo en su notaría. Luego, les hará saber a los interesados y denunciantes, quién tiene derecho a heredar conforme a la ley, y una vez que estén de acuerdo, abrirá el diálogo buscando se nombre a un albacea de la sucesión. Así, se llegará al punto ya establecido en el Código de Procedimientos Civiles como requisito para tramitar la sucesión ante notario, y se seguirá el trámite conforme a aquél.

Para esto, se requieren reformas a los artículos 934 al 938 del Código de Procedimientos Civiles, y al artículo 92 de la ley del notariado, donde se sugiere se establezcan los pasos ya mencionados para poder tramitar la sucesión intestamentaria ante notario desde su inicio. También se propone, para el caso del artículo 3118 del Código Civil del Estado de Jalisco, la modificación al fragmento que señala:

“También en los casos de sucesión legítima, o testamento público cerrado y ológrafo, una vez que hubieren sido reconocidos los herederos, y designado el albacea, podrán los interesados separarse del trámite judicial y concurrir a notaría para la prosecución del negocio.

Cuando haya niñas, niños o adolescentes, podrán separarse, si están debidamente representados y el Agente de la Procuraduría Social da su conformidad. En este caso, los acuerdos que se tomen se denunciarán al Juez, y éste, oyendo a la Procuraduría de Protección de Niñas, Niños..." ${ }^{10}$

Quedando de la siguiente manera:

"Cuando todos los herederos sean mayores de edad, exista testamento público abierto o se requiera promover la sucesión legitima, podrán los interesados tramitar el negocio sucesorio ante notario público que tenga su jurisdicción en el domicilio donde correspondería conocer a la autoridad judicial del mismo, en los términos del Código de Procedimientos Civiles. También en los casos de testamento público cerrado y ológrafo, una vez que hubieren sido reconocidos los herederos, y designado el albacea, podrán los

10 Código civil del Estado de Jalisco. (1996). Jalisco: Gobierno del Estado de Jalisco. Art. 3118. 
interesados separarse del trámite judicial y concurrir a notaría para la prosecución del negocio.

Cuando haya niñas, niños o adolescentes o incapaces, podrán separarse, si están debidamente representados y el Agente de la Procuraduría Social da su conformidad. En este caso, los acuerdos que se tomen se denunciarán al Juez, y éste, oyendo a la Procuraduría de Protección de Niñas, Niños..."

Para lo concerniente al tercer y cuarto párrafo no se contemplan cambios, por lo que estos quedan intocados en el Código.

\section{Bibliografía}

Código Notarial de Costa Rica, Ley No. 7764. (1998). Costa Rica

Ley de Competencia Notarial en Asuntos No Contenciosos. (1996).

Lima, Perú:

Congreso de la República de Perú.

Código civil del Estado de Jalisco. (1996). Jalisco: Gobierno del Estado de Jalisco.

Ley del notariado del Estado de Jalisco. (2007). Guadalajara, Jalisco:

Colegio de Notarios del Estado de Jalisco.

Agraz, C. E. (2001). El derecho notarial en Jalisco. México: Porrúa.

Arellano García, C. (2012). Teoría General del Proceso. México: Porrúa.

Arguello, L. R. (1998). Manual de derecho romano. Buenos Aires: Astrea. Asamblea Legislativa del Distrito Federal. (200). Ley del Notariado del

Distrito Federal. DF: Asamblea Legislativa del Distrito Federal.

Asprón Pelayo, J. M. (2008). Sucesiones. México: Mc Graw Hill.

Baqueiro Rojas, E., \& Buenrostro Báez, R. (2007). Derecho sucesorio.

México: Oxford.

Castro, J. V. (2004). La jurisdicción mexicana. México: Porrúa.

Contreras Vaca, F. J. (2007). Derecho procesal civil. Mexico: Oxford.

García Garrido, M. (1998). Derecho privado Romano. Madrid: Dikyson.

Londoño, R. V. (1988). Ordenes hereditarios, régimen sucesorio notarial: 
Ley 29 de 1982, Ley 45 de 1936, Decreto 902 de 1988, Decreto 999 de 1988, jurisprudencia: Hijos naturales, hijos adoptivos, hijos legítimos. Medellín, Colombia: Señal Editora.

Mustapich, J. M. (1960). Codigo civil de la Republica Argentina: Estudio preliminar. Madrid: Instituto de Cultura Hispanica.

Petit, E. (2011). Tratado Elemental de Derecho Romano. México: Porrúa. Rojina Villegas, R. (1994). Derecho Civil Mexicano IV. México: Porrúa. 
